\title{
Application of laser scanning to measure fragmentation in underground mines
}

\section{A D Campbell}

Senior Geotechnical Engineer - Glencore Copper

PhD Candidate, Sustainable Minerals Institute, University of Queensland, Australia alexander.campbell@glencore.com.au

ORCiD: 0000-0002-1034-1437

\section{J Thurley}

Principal - Innovative Machine Vision Pty Ltd, Melbourne, Australia

Associate Professor Image Analysis - Luleå University of Technology, Sweden

matthew.thurley@imv.net.au

Submitted to Mining Technology Journal: Transactions of the Institutions of Mining and Metallurgy, Section A

Accepted 12 Feb 2017 


\title{
Application of laser scanning to measure fragmentation in underground mines
}

\begin{abstract}
The particle size distribution of fragmented rock in mines significantly affects operational performance of loading equipment, materials handling and crushing systems. A number of methods to measure rock fragmentation exist at present, however these systems have a number of shortcomings in an underground environment. This paper outlines the first implementation of high resolution 3D laser scanning for fragmentation measurement in an underground mine. The system is now used routinely for fragmentation measurement at the Ernest Henry sublevel-cave mine following extensive testing and calibration. The system is being used to study the effects of blasting parameters on rock fragmentation to optimise blast design. Results from 125 three dimensional scans measured the average $\mathrm{P}_{50}$ and $\mathrm{P}_{80}$ to be $230 \mathrm{~mm}$ and $400 \mathrm{~mm}$ respectively. The equipment, methodology and analysis techniques are described in detail to enable application of the measurement system at other mines.
\end{abstract}

Keywords: fragmentation, blasting, mining, sublevel caving, laser scanning

\section{Introduction}

Rock fragmentation by blasting affects the efficiency, productivity and cost of downstream operations including loading, crushing and grinding (Dinis da Gama, 1990; Scott et al., 1999). In addition, the particle size distribution of rock fragmented by blasting is known to influence gravity flow and ore recovery in sublevel cave mines (Laubscher, 1994; Power, 2004). Various gravity flow studies have demonstrated the size of fragmented rock has a direct effect on draw zone geometry and flow mechanisms (Kvapil, 1998; Power, 2004). Larger rock fragments result in larger draw zones and more favourable recovery conditions (Laubscher, 1994), but can lead to dangerous and costly blockages called 'hang-ups'. A number of studies have identified that the size distribution characteristics of fragmented rock has an influence on loading equipment productivity, including the loading cycle time and bucket payload (Allen et al., 1999; Brunton et al., 
2003; Narendula, 2004). Overall, the particle size distribution of fragmented rock in a sublevel cave mine (SLC) mine has an effect on most aspects of operational performance.

Commonly used image base systems for fragmentation measurement have a number of limitations when used underground such as lighting, dust, water and colour which affect particle delineation. Due to the critical importance of fragmentation, a measurement system was required that was accurate, automated, fast, low cost and could be conducted safely at a cave draw point. Using one of the mines existing high-resolution 3D laser scanning systems, a measurement and analysis strategy was implemented, tested and configured in an underground mine at the Ernest Henry Mine (EHM). This system was used to measure a large set of draw point fragmentation data to understand current mine performance and compare various drill and blast design trails in the future.

Testing of the laser scanning system was conducted at the Ernest Henry mine located 38 $\mathrm{km}$ north east of Cloncurry in North West Queensland (see Figure 1). The mine comprises an operating SLC mine below the previous open pit operation. SLC production began after completion of the open pit and targets ore down dip to a depth of almost $1,000 \mathrm{~m}$ as shown in Figure 2.

\section{Fragmentation in caving mines}

The importance of fragmentation in caving mines is outlined by Laubscher (1994) who used scaled physical models to demonstrate that fragmentation size is proportional to the draw zone geometry and should be factored into the design of cave mine layouts to maximise recovery. Laubscher (1994) also noted that fragmentation size affects dilution, draw control practices, draw point productivity and secondary breakage in a block caving environment.

A major difference between model and full-scale gravity flow behaviour is the degree of uniformity, overburden pressure and the large range of particle sizes observed in operational mines. To enable the effect of fragmentation on gravity flow patterns and ore recovery to be understood, an assessment of blasting, fragmentation and recovery must be conducted in a full-scale operational mine. However, to quantify the cause and effect of fragmentation, a reliable and accurate measurement system in an underground environment is required. 


\section{Existing fragmentation assessment methods}

There are a number of methods to measure fragmentation of broken rock including sieving, 2D and 3D image based methods and laser scanning. Sieving (or screening) is the most common method for measuring the size distribution of granular media. However, it is acknowledged in the literature that sieving large volumes of broken rock is both difficult and disruptive in an operating mine and impractical in an underground mining environment (Brown, 2003). Brown (2003) also points out that image-based methods are the only practical method for large-scale fragmentation measurement. This was prior to technological advances that enabled the use of 3D laser scanning for fragmentation measurement (Onederra et al., 2014).

Image based analysis methods for fragmentation measurement were first developed by Carlsson and Nyberg (1983) and Ord (1988). Fragmentation measurement using image analysis provides a fast and inexpensive method for measuring particle size that is less disruptive to mining operations. However, 2D image based assessments have a number of limitations outlined in detail by Sanchidria et al. (2009), Noy (2013) and Thurley (2013). These limitations include particle delineation errors due to lighting and material colour variation, perspective distortion, and an inability to detect areas-of-fines or overlapped particles in a meaningful way.

Thurley $(2002,2014)$ developed a system to conduct fragmentation analysis using 3D laser data that overcomes many of the issues related to $2 \mathrm{D}$ and $3 \mathrm{D}$ image analysis methods. No calibration, scaling or curve fitting is required as the point cloud is a direct measurement of the muck pile. Individually detected particles are classified as areas-offines, overlapped and non-overlapped particles using automated software algorithms as described by Thurley (2009). As with any vision based technique, one can only measure the visible surface of the material meaning size estimations are subject to surface bias due to material segregation. Size estimations are also dependent on the scan resolution which will define a limit below which it is not possible to delineate and size small individual particles. However, the areas-of-visible fines can be detected and included in the combined particle size distribution. 
Fragmentation analysis using 3D laser scanning was applied in an operating open pit by Onederra et al. (2014). Fragmentation measurement using 3D laser scanning in an underground mine was first conducted at EHM in 2014 as a means for safe, fast, accurate and automated fragmentation assessment that negates many of the disadvantages of $2 \mathrm{D}$ image analysis techniques.

\section{System selection}

A number of fragmentation measurement systems were reviewed as part of the blasting and recovery optimisation project at EHM. These systems included visual estimation, sieving, 2D and 3D imaged based methods and laser scanning. The measurement system required the following attributes:

- Data could be collected in a safe manner and does not require a draw point to be approached to place scale markers on the rill pile and can be conducted behind a safety bund.

- Low cost and highly repeatable.

- Not affected by lighting issues in an underground mine.

- Not affected by colour or reflectance such as particles covered in water or dust.

- Fast and can be conducted without disruption to normal mining operations.

- Accurate enough to measure particles as small as $25 \mathrm{~mm}$.

- Automated analysis software.

A visual estimation method using reference photos was used at the mine prior to this project for simple comparison fragmentation estimation. This method was quick and simple, but lacked the accuracy and consistency required for blast optimisation research. Sieving was also considered, but was not practical at the mine.

A 2D image based method for fragmentation was trialled underground. Photos were easily affected by dust in the air and muck piles needed to be washed down to remove dust from the surface to improve particle delineation. Site personnel found the automated processing function was not representative of the observed particle sizes due to splitting of large rocks into multiple size fragments. As a result, processing using manual editing was required to produce representative size distribution data and took approximately one hour per image. For these reasons, 2D image based methods were discontinued at the 
mine. A 3D image system based on stereo photogrammetry was also tested at the mine. Like the 2D image method, it was fast and simple to use, but suffered the same shortcomings.

Following testing of available fragmentation measurement technology, it became apparent that no current system was available that could meet the project requirements. Onederra et. al. (2014) demonstrated the use of an automated 3D high-resolution laser scanning method that met most of the requirements identified. Test measurements were performed at EHM using 15 underground scans to configure the analysis algorithms and demonstrated the system could provide reliable fragmentation measurements in an underground environment.

\section{Laser scanning equipment and methodology}

Draw point laser scanning is conducted from behind a safety bund which acts as a barrier should rocks dislodge from the muck pile or draw point brow. The laser scanner is raised almost to the drive backs (around $4.5 \mathrm{~m}$ high) on a hydraulic prop mounted on the underground vehicle as shown in Figure 3. This enables the scanner to measure all of the rill pile over the safety bund, as well as scanning at an angle to the pile surface as close to 90 degrees as practical. The scanning technique also negates the need to place scale markers on the rill pile which can be unstable and prohibited to access at some underground mines.

A scan angle of 0.02 degrees is used with the $450 \mathrm{~m}$ range setting which results in laser pulse repetition rate of $300 \mathrm{kHz}$ resulting in 122,000 measurements per second. This enables a draw point to be scanned in approximately 2-3 minutes. This scan resolution results in point spacing of around $2 \mathrm{~mm}$ or 4 to 8 million points for a draw point scan. The total set-up and demobilisation time is in the order of several minutes making the total time at the draw point around 10 minutes per scan. Once scanning has been completed, the point data is then trimmed for the area of interest and the automated fragmentation analysis completed.

\section{Data processing and analysis}

Raw scan data of the draw point was cropped manually to remove any parts of the floor, walls and roof of the tunnel before analysis. The subsequent analysis is an automatic 
process with no manual intervention required for non-contaminated input data and consisted of the following steps:

1. Filtering the $3 \mathrm{D} x, y, z$ data to remove erroneous $3 \mathrm{D}$ points.

2. Orthogonally re-projecting the data (also known as perspective normalisation). This process involves transforming the 3D data so the measurement rays from the scanner are remapped to be orthogonal to the viewing plane and parallel to each other. This allows for simplicity in noise filtering and particle delineation.

3. Perform particle delineation.

4. Classification of the detected particles into areas-of-fines, overlapped particles, and non-overlapped particles by analysing the 3D topology of the particle and its surrounds as described by Thurley (2009).

5. Back projecting the data to the original perspective projection.

6. Sizing and data reporting.

The particle delineation approach is based on watershed segmentation and morphological operators. The following is an overview of the analysis approach with detail presented in Thurley (2013).

1. Edge detection is performed using a morphological gradient with a spherical structuring element and then thresholded to classify edges.

2. Seed formation for the watershed segmentation is performed using a three-step process based on distance transform, local maxima, and seed merging.

3. Watershed segmentation based on the seed regions is applied to the rock pile data after which a filter is applied to remove small "noise" regions.

On occasion, there was steel mesh or a rock bolt on the rock pile and these objects disturb the measured 3D surface profile of the rocks causing some rocks to be delineated into smaller parts. These rocks can be manually delineated before analysis if required. In practise this is only necessary for large rocks that would have a significant impact on the resultant size distribution curve. Manual delineation of 1 or 2 large rocks was required for 11 of the 125 data sets.

Classification is performed to identify delineated regions as areas-of-fines, overlapped particles, and non-overlapped particles. This distinction is a key advantage of the presented system as it ensures that overlapped particles (analogous to ice-bergs) are not 
sized based on their visible profile preventing an underestimation of size and error towards smaller sizes. Furthermore, it ensures that areas-of-fines are not incorrectly identified as large rocks preventing a large error towards larger sizes. Mitigating these opposing sources of error results in a stable and reliable measurement system. Thurley (2014) demonstrates the capacity of these algorithms to detect significant size variation that would otherwise fail to be observed.

To adjust the system for operation in the measured draw point geometry, a new classifier for areas-of-fines was developed. The areas-of-fines were manually specified using eight data sets to build the classifier, then the automatic analysis was compared against these manual sets to define which parts of the automatic delineation were fines and which were not. Thereafter, features were calculated for each delineated region including the region size, the "visibility ratio" (Thurley and $\mathrm{Ng}, 2008$ ) which is a measure of the degree to which a particle is above its neighbours, and a height measure that characterises the relative height difference of the particle to its neighbours (Thurley, 2009). Using these features a binomial logistic regression was performed to produce a classification function indicating the probability that a given region is fines. Then it is possible to set the threshold to accept regions as fines at any given level depending on the amount of false fines detection that can be tolerated. In this work the threshold was set to be conservative in fines detection to prevent large rocks being falsely detected as areas-of-fines. Regions not classified as areas-of-fines are further classified into non-overlapped and overlapped particles based on the "visibility ratio" (Thurley and Ng, 2008). Regions classified as overlapped particles are excluded from further analysis as they are analogous to ice-bergs and their visible surface profile is an unreliable estimate of their size.

Sizing is performed on the non-overlapped particles and areas-of-fines (as shown in Figure 4). Particles classified as areas-of-fines are allocated to a fines size class. The fines size class is dependent on the point resolution of each individual data set but is typically $25 \mathrm{~mm}$ or less. Non-overlapped regions are sized based on the projection of the region onto the $2 \mathrm{D}$ viewing plane and calculation of the width of the best-fit rectangle of the region.

Two size distributions are produced, one based on an estimation of the particle volume, and the other based on the calculated particle area. A cumulative size distribution is 
produced using the size of each particle, and the calculated area or volume respectively. For the volume based distribution, an ellipsoid volume is calculated for each nonoverlapped particle with length, width, height respectively based on the length, width and width of the calculated best-fit-rectangle. For areas-of-fines in the volume based distribution, the best-fit-rectangle area is also calculated, and this is scaled by an arbitrary depth factor parameter of $250 \mathrm{~mm}$. For the area based distribution, the area of the best-fitrectangle is calculated for both the non-overlapped particles and areas-of-fines.

The volume size distribution curves have two notable disadvantages over the area curves. Firstly, they require an arbitrary scaling factor for the fines, in this case $250 \mathrm{~mm}$. The depth of $250 \mathrm{~mm}$ was selected to match the $\mathrm{P}_{50}$ measured in scans conducted in the system development and calibration phase. Secondly, volume curves are heavily biased towards larger particles because the volume of these particles is proportionately much larger. Larger rocks are more likely to be visible on the surface of the pile simply because they are larger, and smaller rocks visible on the surface are indicative of a higher proportion of these rocks throughout the pile in the case of a well-mixed pile. There is a non-uniform probably of rocks being visible on the surface of the pile relative to their size and this has previously been described as "capturing error" and detailed further by Thurley (2002). The area curves significantly mitigate this bias providing increased emphasis on smaller size fractions, and provide a better basis for comparison of the whole size distribution curve.

\section{Scan resolution testing}

Resolution testing was conducted for 40 scans at 10 separate draw points to determine the most suitable scanner settings to be used for the fragmentation study. During each test, scanning was conducted at an angular resolution of $0.03,0.02,0.015$ and 0.01 degrees. An example of a scan resolution test is shown in Figure 5.

It is evident in the fragmentation results that the effect of the scan resolution for the setting selected is relatively low. This is demonstrated by the closely matched particle size distribution curves shown in Figure 6. The $\mathrm{P}_{20}, \mathrm{P}_{50}$ and $\mathrm{P}_{80}$ size fractions are also similar for the various scan resolutions and provided in Table 1. The main difference in results from a high-resolution scan to a low-resolution scan was found to be the minimum size 
particle that could be delineated, fines detection accuracy and the total number of particles delineated.

Material from the SLC is tipped into the orepass to move material to the underground crusher. The flow of ore causes significant amounts of breakage and fines generation. A number of orepass draw points were scanned as part of the resolution testing to determine the effect of scan resolution on fines detection. Overall, particle detection and fines content were measured consistently for scan resolution of 0.01 degrees and 0.02 degrees as shown in Figure 7. This demonstrates that very high scan resolutions are not necessary for accurate fines detection.

The higher resolution scans had the disadvantage of significantly longer scanning time (around 10 minutes) and very large files sizes (up to $200 \mathrm{Mb}$ ). These disadvantages and the comparison of the 40 resolution tests led to the decision that the 0.02 degrees separation was the most suitable setting for draw point fragmentation assessment in an underground mine.

\section{Fragmentation measurement results}

Fragmentation data from any imaging sensor or laser scanner has the disadvantage that only the surface of the draw point rill can be measured. However, the surface measurements do enable relative comparisons to be made, such as the difference in fragmentation between different drill and blast designs.

A total of 125 fragmentation measures were conducted to form the baseline dataset so that results of future drill and blast experiments could be compared. Fragmentation measurements were taken after blasting, then every 250 tonnes until 1000 tonnes extraction and then every 500 tonnes until the prescribed draw was reached (generally around 5000 tonnes). Results from multiple scans from a single drawpoint were assessed individually and as combined datasets. The combined dataset was determined by merging the fragmentation of each scan into a single dataset.

Material larger than $1200 \mathrm{~mm}$ is classed as oversize at the Ernest Henry mine and requires secondary breakage prior to being tipped into the orepass system. Between $1 \%$ and $2 \%$ of the total mine production tonnes are recorded as oversize. This corresponds closely to 
the measured fragmentation data which has an average of $1.1 \%$ material greater than $1200 \mathrm{~mm}$. Overall it was found that the variability in size distribution was significant between fragmentation scans, though size distributions generally occurred within a relatively narrow band. The overall dataset also demonstrates relatively similar fragmentation when all the scan data for a draw point was combined into a single size distribution and compared to other draw points (shown in Figure 8 and Table 2). It is intended that similar datasets for different drill and blast designs will be compared to quantify the effect blast design variables on fragmentation.

\section{Conclusions}

This paper outlined the application, testing and configuration of a high-resolution 3D laser scanning for fragmentation measurement in an underground mine. This is the first application of laser scanning for automated fragmentation analysis underground and was developed to overcome limitations of image based analysis methods.

Testing of various scan resolutions found that increasing the point cloud density resulted in no significant change in particle size distribution despite increasing the number of particle detections. A total of 125 measurements was used to quantify the size distribution of blasted material at the mine.

It is known that the particle size distribution of fragmented rock in a SLC mine has an effect on most aspects of operational performance including loading equipment productivity, gravity flow and ore recovery, secondary breakage, crushing and grinding. With the development of the laser scanning system, rapid measurement and development of large datasets is now possible. Fragmentation measurement using the developed laser scanning system has enabled the mine to compile one of the largest datasets for fragmentation analysis in a sublevel cave published to date. This data will be compared to ongoing fragmentation measurements for a number of experiments in order to quantify the effect of blast design variables on fragmentation and identify opportunities to improve ore recovery and the potential to reduce blasting costs.

Word count -3488 


\section{References}

Allen, F, Hawkes, P and Noy, M. 1999. Bucket fill factors - A laboratory and field study with implications for blasting, in Explo 99, Kalgoorlie, WA pp. 43-6.

Brown, ET. 2003. Block caving geomechanics, The International Caving Study, Stage I 1997-2000, Julius Kruttschnitt Mineral Research Centre, Indooroopilly, Australia.

Brunton, I, Thornton, D, Hodson, R and Sprott, D. 2003. Impact of Blast Fragmentation on Hydraulic Excavator Dig Time, in Fifth Large Open Pit Mining Conference, Kalgoorlie, Western Australia, pp. 39-48.

Carlsson, O and Nyberg, L. 1983. A method for estimation of fragmentation size distribution with automatic image processing, in First International Symposium on Rock Fragmentation by Blasting- Fragblast, Lulea, Sweden, pp. 333-45.

Dinis da Gama, C. 1990. Reduction of cost and environmental impacts in quarry rock blasting, in Third International Symposium on Rock Fragmentation by Blasting, Melbourne, pp. 5-8

Kvapil, R. 1998. Mechanics and design of sublevel caving systems, in REaB Ed. Gertsch, R.,L (ed.), Techniques in Underground Mining,, Society for Mining, Metallurgy, and Exploration, Inc., Littleton, CO, USA, pp 621.

Laubscher, DH. 1994. Cave mining - the state of the art, Journal of the South African Institute of Mining and Metallurgy, October.

Narendula, R. 2004. Effect of fragmentation on productivity on loading equipment, Master of Applied Science thesis, Laurentian University.

Noy, MJ. 2013. Automated rock fragmentation measurement with close range digital photogrametry, in SS (Eds) (ed.), Measurement and Analysis of Blast Fragmentation, CRC Press 2012, pp 13-21.

Onederra, I, Thurley, MJ and Catalan, A. 2014. Measuring blast fragmentation at Esperanza mine using high-resolution 3D laser scanning, Mining Technology, vol. 124 , no. 1 , pp. 34-6.

Ord, A. 1988. Real-time image analysis of size and shape distributions of rock fragments, paper presented to Explosives in Mining Workshop, Melbourne.

Power, GR. 2004. Modelling granular flow in caving mines: large scale physical modelling and full scale experiments, $\mathrm{PhD}$ thesis, University of Queensland. 
Sanchidria, JA, Segarra, P, Ouchterlony, F and Lopez, LM. 2009. On the accuracy of fragment size measurement by image analysis in combination with some distribution functions, Rock Mechanics and Rock Engineering, vol. 42, pp 95116.

Scott, A, Kanchibotla, S and Morrell, S. 1999. Blasting for Mine to Mill Optimisation, paper presented to In Proceedings Explo 99.

Thurley, MJ. 2002. Three dimensional data analysis for the separation and sizing of rockpiles in mining, $\mathrm{PhD}$ thesis, Monash University, Australia

Thurley, $\mathrm{M}$ and $\mathrm{Ng}, \mathrm{K}$. 2008. Identification and sizing of the entirely visible rocks from a 3D surface data segmentation of laboratory rock piles, Computer Vision and Image Understanding, vol 111, no. 2, pp. 170-178.

Thurley, MJ. 2009. Fragmentation size measurement using 3D surface imaging (in LHD buckets), Proceedings of the Ninth International Symposium on Rock Fragmentation by Blasting - Fragblast 9, Granada, Spain.

Thurley, MJ. 2013. Automated image segmentation and analysis of rock piles in an open-pit mine, 2013 International Conference on Digital Image Computing: Techniques and Applications Hobart, Australia, 26-28 November 2013.

Thurley, MJ. 2014. Measuring the visible particles for automated online particle size distribution estimation, Proceedings of the XXVII International Mineral Processing Congress: IMPC 2014, 20-24 October 2014, Santiago, Chile Thurley, MJ and Andersson, T. 2008. An industrial 3D vision system for size measurement of iron ore green pellets using morphological image segmentation, Minerals Engineering, vol. 21, no. 5, pp. 405-15. 
Table 1. Results of resolution scan data shown in

Figure

\begin{tabular}{|c|c|c|c|c|c|c|c|c|}
\hline $\begin{array}{l}\text { Scan } \\
\text { resolution }\end{array}$ & $\begin{array}{l}\text { Number of } \\
\text { Particles }\end{array}$ & $\begin{array}{l}\text { Mean size } \\
(\mathrm{mm})\end{array}$ & $\begin{array}{l}\mathrm{P}_{20} \\
(\mathrm{~mm})\end{array}$ & $\begin{array}{l}\mathrm{P}_{50} \\
(\mathrm{~mm})\end{array}$ & $\begin{array}{l}\mathrm{P}_{80} \\
(\mathrm{~mm})\end{array}$ & $\begin{array}{l}\text { Fines } \\
(<50 \mathrm{~mm})\end{array}$ & $\begin{array}{l}\text { Measured } \\
\text { Minimum } \\
(\mathrm{mm})\end{array}$ & $\begin{array}{l}\text { Measured } \\
\text { Maximum } \\
(\mathrm{mm})\end{array}$ \\
\hline $0.01 \mathrm{deg}$ & 934 & 123 & 152 & 269 & 416 & $2 \%$ & 10.5 & 672 \\
\hline $0.015 \mathrm{deg}$ & 793 & 136 & 165 & 277 & 415 & $2 \%$ & 12 & 683 \\
\hline $0.02 \mathrm{deg}$ & 724 & 142 & 162 & 279 & 404 & $2 \%$ & 16.5 & 685 \\
\hline $0.03 \mathrm{deg}$ & 608 & 155 & 169 & 296 & 436 & $1 \%$ & 22.5 & 661 \\
\hline
\end{tabular}

Table 2. Summary of 125 fragmentation measurements for 10 blast rings (measurements by 'area')

\begin{tabular}{cccccc} 
Ring & $\begin{array}{c}\text { Number of } \\
\text { measurements }\end{array}$ & $\begin{array}{c}\% \text { Fines } \\
(<50 \mathrm{~mm})\end{array}$ & $\mathrm{P}_{50}(\mathrm{~mm})$ & $\mathrm{P}_{80}(\mathrm{~mm})$ & $\begin{array}{c}\% \text { Oversize } \\
(>1200 \mathrm{~mm})\end{array}$ \\
OD9 R37 & 15 & $16.2 \%$ & 222 & 364 & $0.0 \%$ \\
OD9 R38 & 15 & $12.0 \%$ & 235 & 381 & $0.6 \%$ \\
OD9 R39 & 13 & $14.4 \%$ & 232 & 375 & $0.0 \%$ \\
OD9 R40 & 10 & $13.1 \%$ & 213 & 398 & $1.0 \%$ \\
OD11 R34 & 6 & $4.9 \%$ & 251 & 406 & $0.0 \%$ \\
OD11 R36 & 13 & $13.9 \%$ & 252 & 398 & $1.1 \%$ \\
OD11 R37 & 15 & $11.6 \%$ & 215 & 392 & $3.8 \%$ \\
OD11 R38 & 14 & $17.5 \%$ & 204 & 353 & $0.0 \%$ \\
OD11 R39 & 15 & $12.7 \%$ & 215 & 407 & $0.6 \%$ \\
OD11 R40 & 9 & $12.0 \%$ & 245 & 510 & $4.2 \%$ \\
\hline Average & & $12.8 \%$ & 228.5 & 398.6 & $1.1 \%$
\end{tabular}


Figure 1. Location of Ernest Henry and Australian Glencore Copper Operations

Figure 2. Perspective view of the mine including the SLC and underground infrastructure

Figure 3. Set-up of the laser scanner at a draw point (left) and close-up of the Riegl VZ1000 laser scanner and camera attachment (right)

Figure 4. Example of a laser scan and particle delineation. A) Processed scan, B) Area of fines, C) Non-overlapped particles

Figure 5. An example of a scan resolution test showing the non-overlapped particles. Scan angle setting of A) 0.01 degrees, B) 0.015 degrees, C) 0.02 degrees, D) 0.03 degrees.

Figure 6. Particle size distribution of scans conducted at a draw point shown in Figure 5

Figure 7. Scan resolution testing in orepass draw points with high fines content

Figure 8. Combined particle size distributions for the 125 baseline fragmentation measurements for 10 draw points 


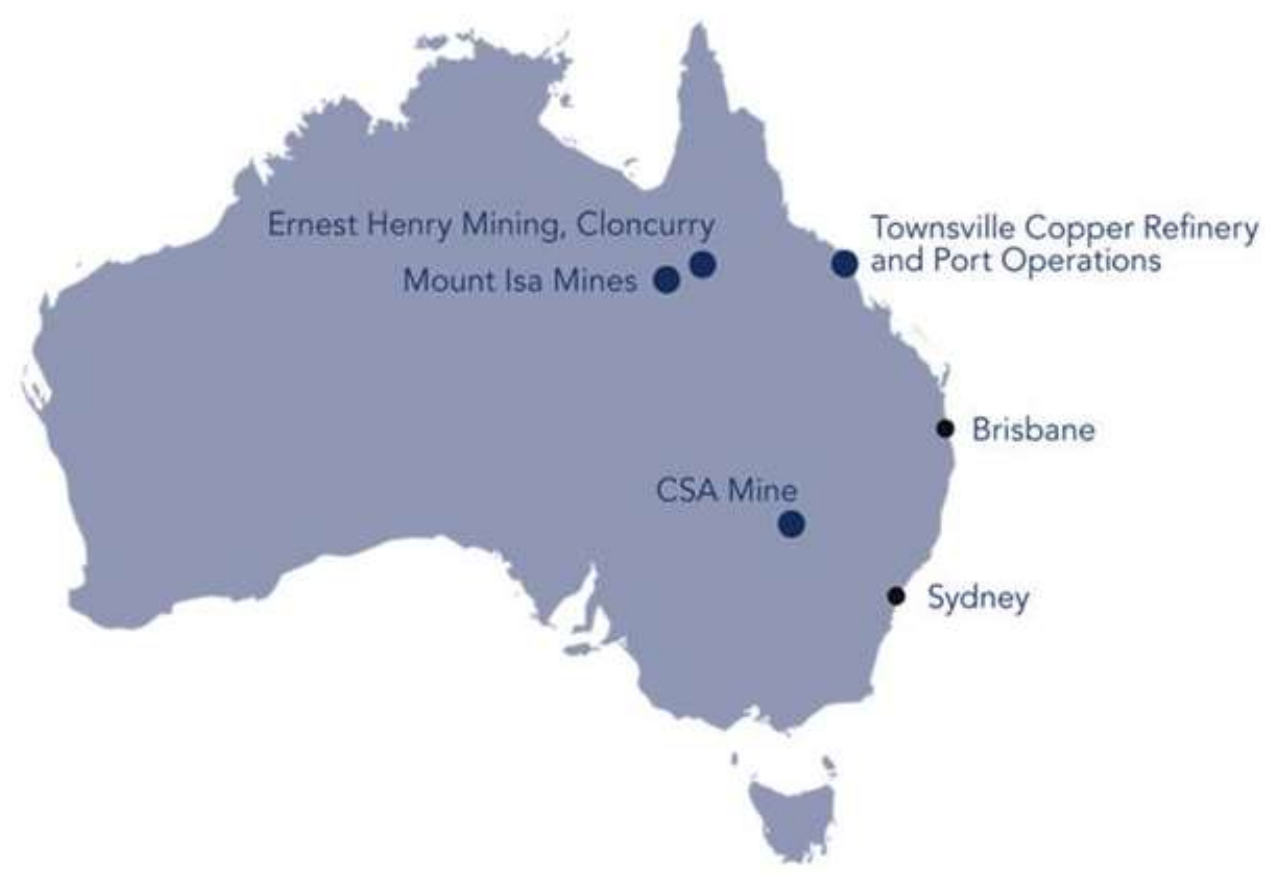

Figure 1. Location of Ernest Henry and Australian Glencore Copper Operations

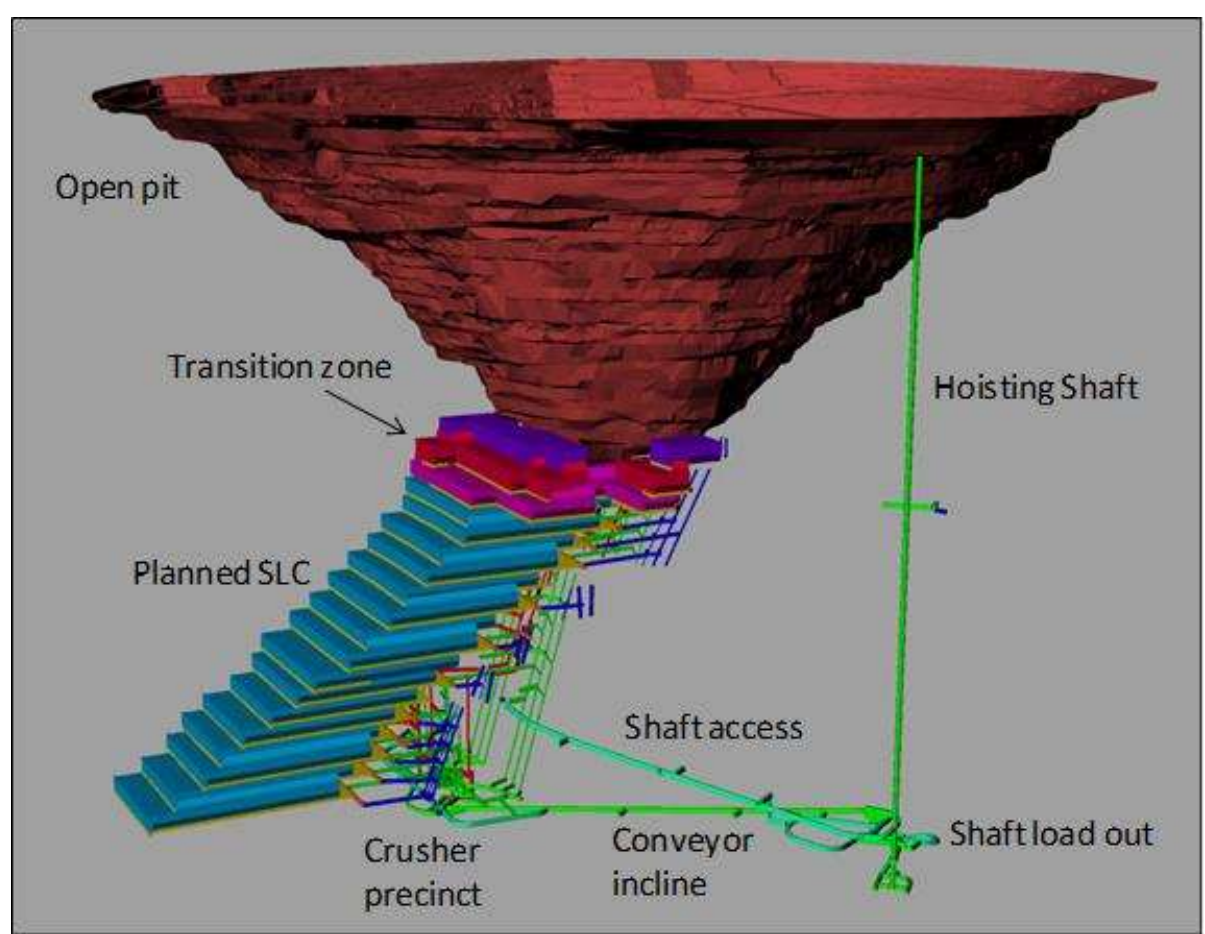

Figure 2. Perspective view of the mine including the SLC and underground infrastructure 

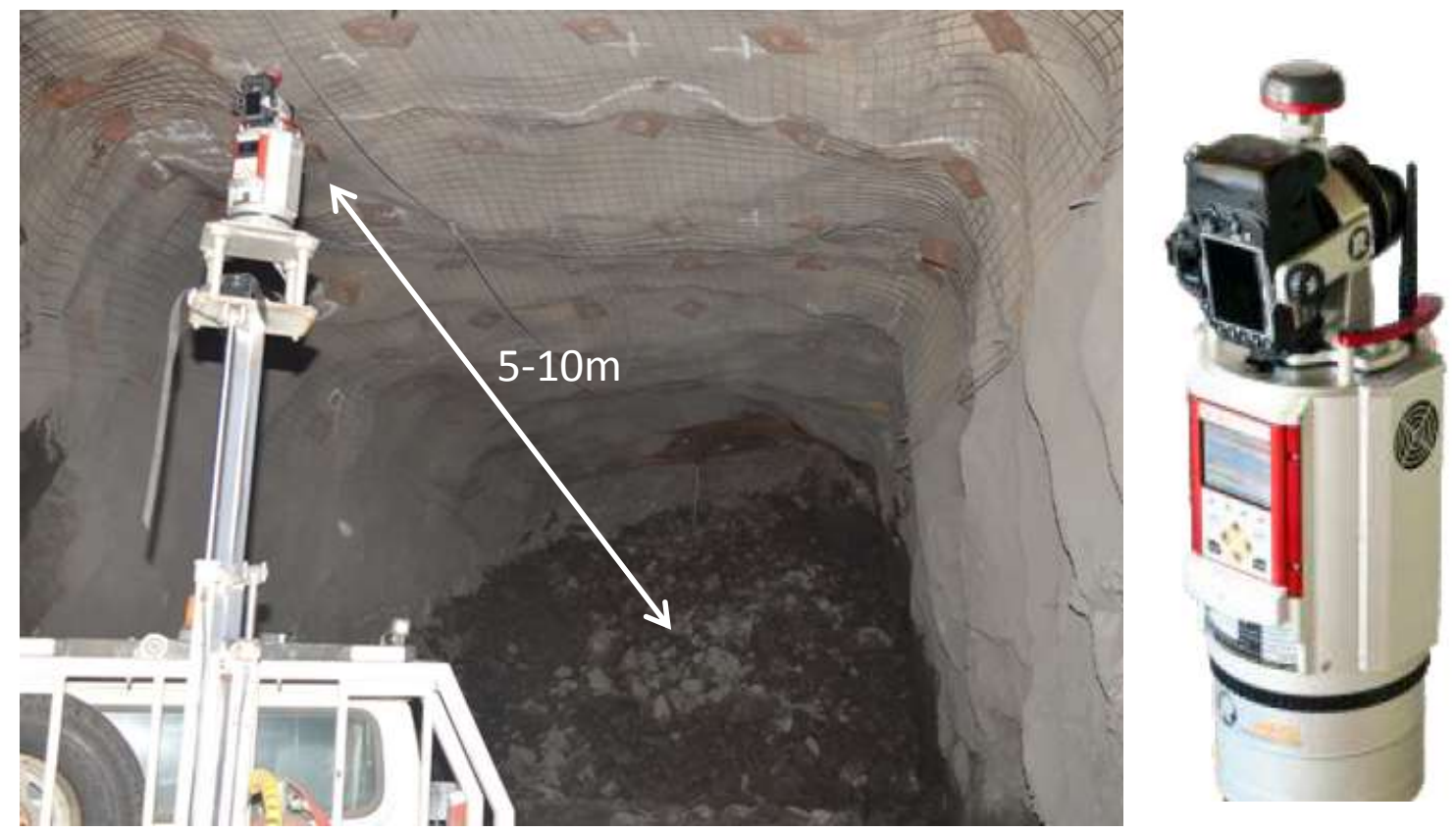

Figure 3. Set-up of the laser scanner at a draw point (left) and close-up of the Riegl

VZ1000 laser scanner and camera attachment (right)

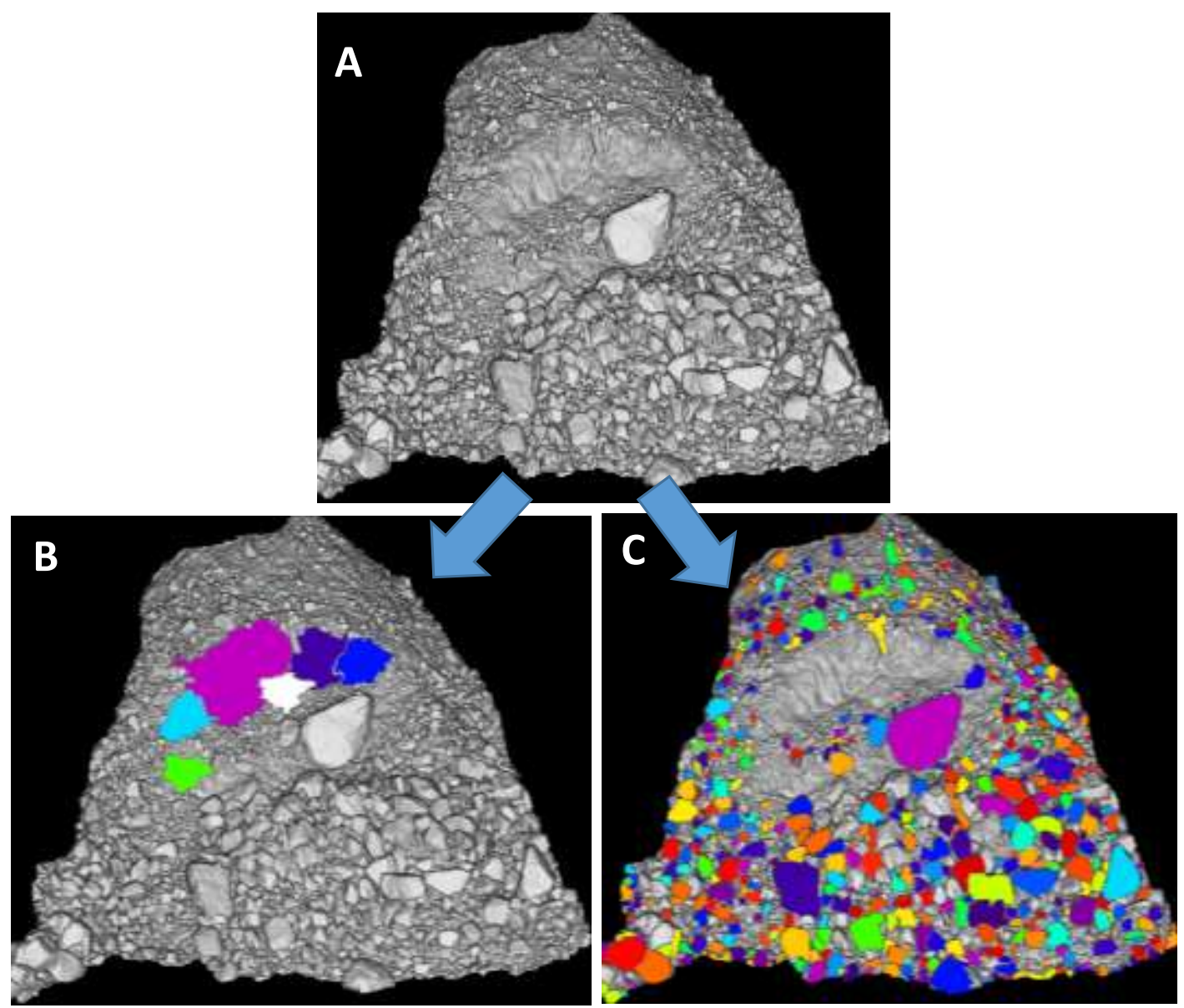

Figure 4. Example of a laser scan and particle delineation. A) Processed scan, B) Area of fines, C) Non-overlapped particles 

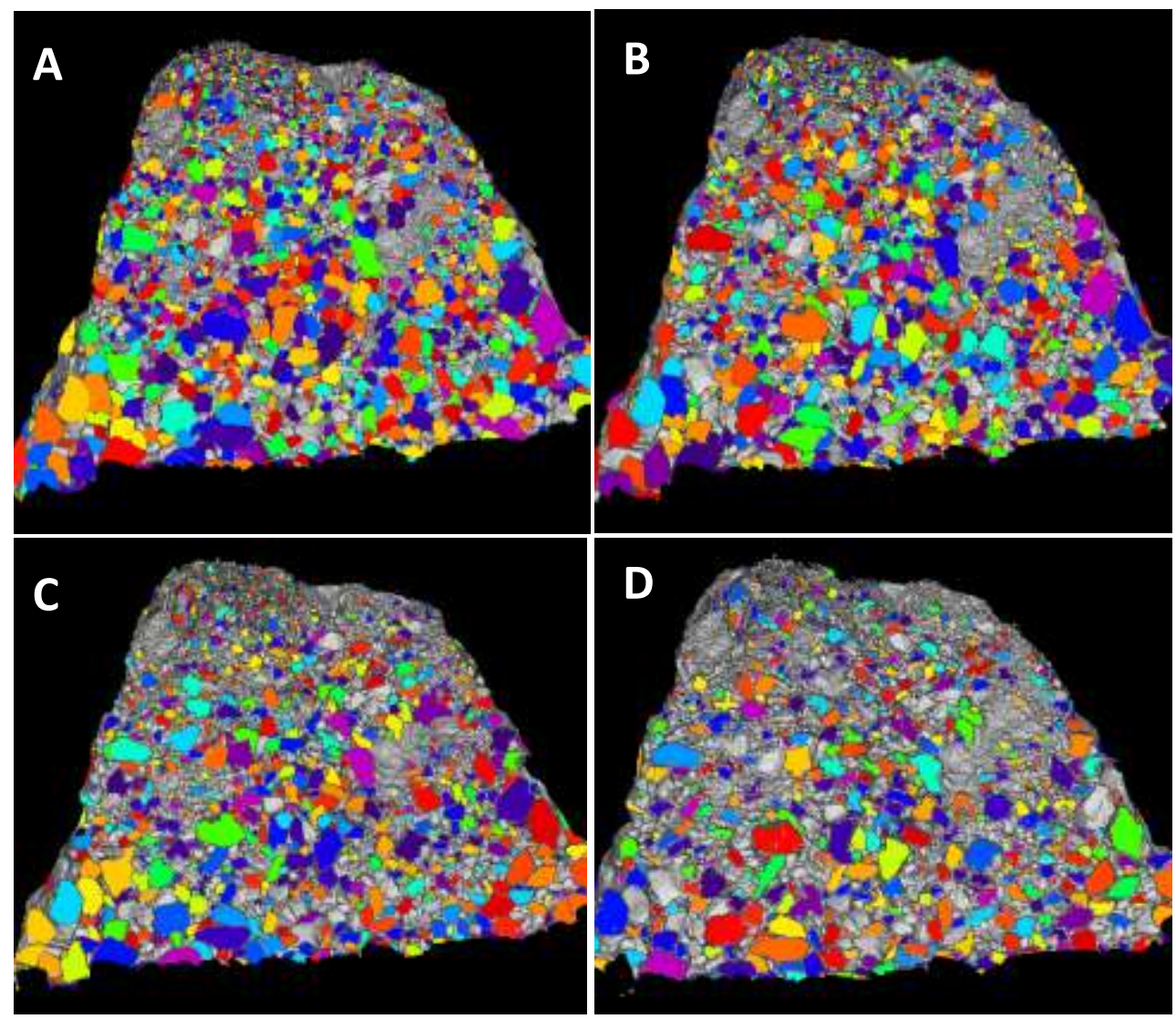

Figure 5. An example of a scan resolution test showing the non-overlapped particles.

Scan angle setting of A) 0.01 degrees, B) 0.015 degrees, C) 0.02 degrees, D) 0.03 degrees. 


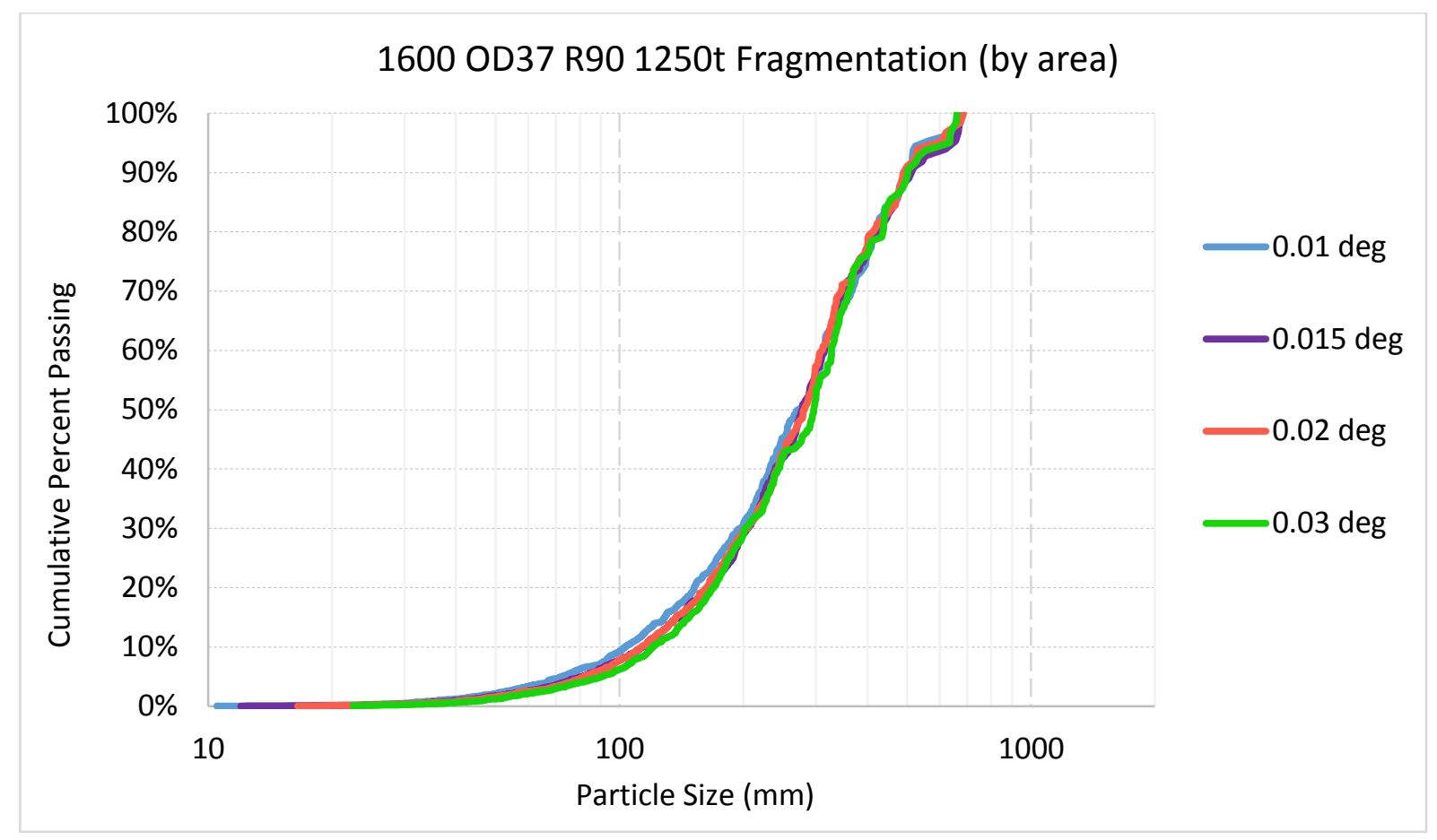

Figure 6. Particle size distribution of scans conducted at a draw point shown in Figure 5

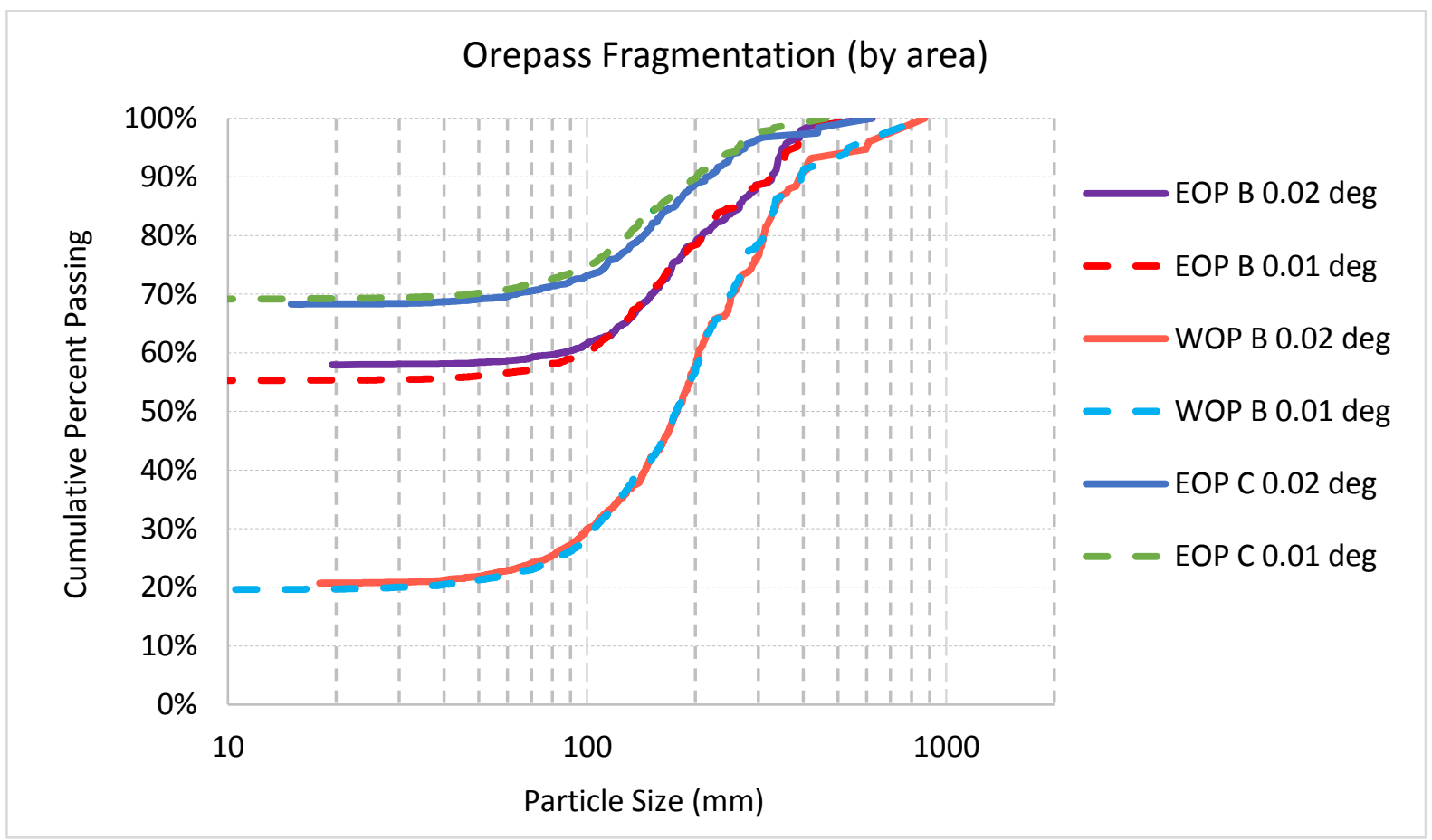

Figure 7. Scan resolution testing in orepass draw points with high fines content 


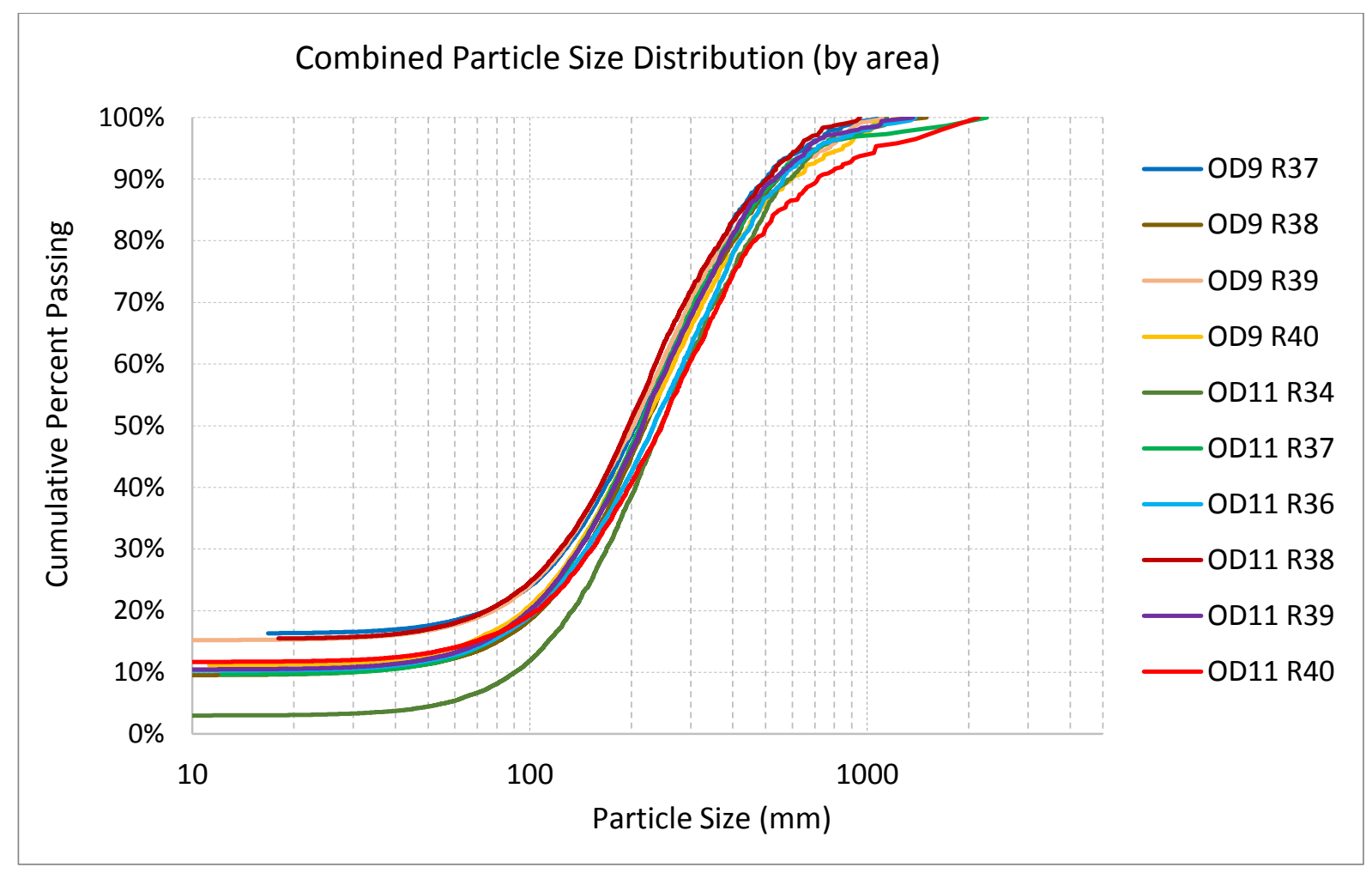

Figure 8. Combined particle size distributions for the 125 baseline fragmentation measurements for 10 draw points 